\title{
DOSSIÊ
}

\section{LITERATURA PARAGUAY/GUARANÍ - TRANSVERSALIDADES}

\section{POR DAMIÁN CABRERA}

RESUMO Passando por trabalhos compilatórios
dos escritores paraguaios Augusto Roa Bastos e Rubén Bareiro Saguier, e a partir de discursos literários e não literários, analisa-se a ambiguidade fundada na palavra guarani; que designa, indistintamente, uma língua, uma cultura, uma etnia; e que, por metonímia, constitui-se em apelido-gentílico dos paraguaios. Relações entre literatura paraguaia e literatura Guarani são exploradas, desde a perspectiva dos autores citados; tanto conhecedores e divulgadores da mesma, como dois dos poucos paraguaios capazes de ultrapassar um cerco de isolamento cultural graças, em parte, ao exílio político; sob a luz de uma tradição crítica latino-americana hispanizante que, enquanto invisibiliza a literatura paraguaia, contribui com uma mistificação dela, fundada em sua peculiaridade linguística, seja ela real ou inventada.
PARAGUAYAN/GUARANI

LITERATURE TRANSVERSALITIES

ABSTRACT Going through compilation works of Paraguayan writers Augusto Roa Bastos and Rubén Bareiro Saguier, and from literary and nonliterary discourses, the ambiguity founded in the word guarani is analyzed; which indistinctly designates a language, a culture, and an ethnic group; and which, by metonymy, is a demonymnickname for Paraguayans. Relations between Paraguayan and Guarani literature are explored, from the perspective of the cited authors; both connoisseurs and disseminators of Guarani literature, as two of the few Paraguayans able to overcome a siege of cultural isolation thanks, in part, to the political exile; 
in the light of an

hizpanicying Latin

American critical tradition

that, as well as invisibilizes

Paraguayan literature,

contributes to a

mystification founded in its

linguistic peculiarity,

whether real or invented.

PALAVRAS-CHAVE $\underline{\text { Literatura }} \underline{\text { Paraguai }}$ Guarani KEY WORDS Literature Paraguay Guarani

Llama la atención que la memoria de una nación como la paraguaya que siempre ha tenido como propia la lengua guarani- haya sido historiada por personas que, aun conociendo dicha lengua, se ha abstenido de ella en la construcción de sus relatos. Bartomeu Melià

\section{BIPOLARIDADES}

Mestizaje hispano-guaraní: bajo la superficie de este mito, fundacional del nacionalismo paraguayo, es posible entrever inestabilidades. Nombre compuesto bajo el cual podría ser imaginada una solución armónica entre dos términos opuestos y sus universos simbólicos - el colonial y el indígena-, en él están implicadas negaciones e invisibilización de uno de sus componentes, el indígena, en favor de la cultura colonial que ha signado los horizontes de la sociedad paraguaya desde múltiples perspectivas, incluyendo la simbólica y la económica. El mito, su discurso y sus iconografías buscan limar superficialmente las rugosidades en las que se basa esta relación tensa desde sus primeras fechas. A su vez, imbricadas en estas tensiones irregulares entre estos dos polos, reflexiones y producciones simbólicas han proliferado tratando de sortear distancias en favor de la construcción de la identidad nacional paraguaya, o han contestado las operaciones de esta búsqueda y los usos ideológicos de sus productos.

La constatación ineludible de que la mayoría de la sociedad paraguaya, aún hoy, habla guaraní habilita un horizonte ambiguo que requiere de cierta transparencia: aunque su lengua sea el guaraní, la sociedad paraguaya no es Guaraní, aun cuando se autodenomine guaraní. Los usos conservadores y progresistas del indigenismo se han perdido en esta ambivalencia del nombre, o no han sabido nombrar aisladamente procesos y expedientes que se traspapelaron arrojando sombra sobre territorios específicos de la diferencia o provocando indiferencia frente a programas homogeneizadores y autoritarios que han sostenido, paradójicamente, su negación. 
Como principal legado de la cultura Guaraní a la sociedad paraguaya, esta lengua, y su relación tensa, primero, con el castellano y, luego, con lenguas pertenecientes a diversas colectividades de inmigrantes, ha sido nuclear en las reflexiones sobre la producción literaria en Paraguay y aun su tensión, resuelta a través de expedientes diversos, ha tenido su importancia en las literaturas populares y eruditas del Paraguay[1].

El guaraní es la lengua mayoritaria de la sociedad paraguaya y es una lengua subalterna. Esta condición de subalternidad ha signado la búsqueda de una escritura con voz propia en autores populares y "eruditos", en escenas rurales y urbanas, y ha sido una preocupación central en la producción de algunos autores que podrían ser considerados canónicos de una modernidad - tardía con respecto a la región - con resultados disímiles y algunas coincidencias: este artículo se concentra en el discurso producido por y sobre Augusto Roa Bastos[2] y Rubén Bareiro Saguier[3], y en torno a su producción intelectual no literaria que podría ser leída bajo los signos de una transversalidad indigenista entre literatura paraguaya y cultura Guaraní.

Augusto Roa Bastos es el autor paraguayo más internacionalizado; ganador del Premio Cervantes en 1989, sus novelas alcanzaron, sin embargo, una difusión marginal frente a los autores del boom latinoamericano al cual crítica y editorialmente se lo ha adscripto, no sin impugnaciones[4]; su novela $\mathrm{Yo}$ el Supremo es considerada su obra cumbre, en una serie en la que reflexiona sobre el poder y, eventualmente, sobre el lenguaje - reflexión a la luz de la cual es descripta por Saúl Sosnowski y aun por el propio Rubén Bareiro Saguier-. Como Roa Bastos, Rubén Bareiro Saguier produjo la mayor parte de su obra fuera del Paraguay, fundamentalmente desde Francia; perteneciente al ámbito académico y conocedor de la lengua guaraní produjo conocimiento sobre ella así como fue el responsable de la mayor compilación de literatura Guaraní que se ha puesto en circulación. Sus vidas y sus obras estuvieron marcadas por el exilio que les impuso la dictadura stronista, la más larga del Cono Sur.

Sin embargo, a pesar del interés de estos autores por la lengua guaraní y aun por la literatura Guaraní, ellos han escrito fundamentalmente en castellano; y aun sus trabajos compilatorios de las tradiciones orales indígenas han circulado en versiones traducidas. Su afán por dotar de visibilidad a una cultura y una tradición literaria oral otra ha operado fuera de la lengua en la que éstas tienen hogar; acaso la anulación del porvenir y la distancia impuesta por el exilio les habían obligado a pensar en sus nuevos interlocutores posibles; sin mencionar que tanto sus obras literarias como su pensamiento se corresponden con una época de debilitamiento de las fronteras y, más allá de las identidades nacionales, en busca de la expresión latinoamericana, por parafrasear a Pedro Henríquez Ureña; y como se vería, al decir de Cornejo Polar, "en el ámbito de la literatura latinoamericana (...) el concepto de literatura nacional está sujeto a la presión de categorías mayores, regionales o subregionales, que cada vez cobran mayor peso y realidad verificable" (CORNEJO POLAR, 1978, p. 9). 
Opositores de un indigenismo nacionalista en Paraguay, que operaba fundamentalmente vaciando de lo indígena las representaciones de los Guaraníes, se podría afirmar que la obra indigenista de ambos autores ha concentrado esfuerzos en hacer visible una denuncia de las condiciones hostiles de subsistencia de muchas comunidades indígenas, así como en poner en circulación su producción simbólica con el objeto de suscitar una valoración de una cultura ignorada más allá de una lengua celebrada por el nacionalismo paraguayo como componente de identidad nacional: lengua, por lo demás, subalterna y colonizada, vaciada en gran medida de sus significados Guaraníes fundamentales.

\section{INDIGENISMO: UNA TRANSVERSALIDAD}

Examinando las principales fórmulas del americanismo en la literatura latinoamericana, Pedro Henríquez Ureña señala que, precedida por una literatura descriptiva concentrada en la naturaleza, advino en las literaturas latinoamericanas una búsqueda indigenista: “ ¡Ir hacia el indio! Programa que nace y renace en cada generación bajo muchedumbre de formas, en todas las artes" (UREÑA, 1960, p. 247). Este programa ha sido problematizado desde diversas perspectivas, entre ellas el lugar de enunciación desde el cual se profieren producciones simbólicas y defensas del indígena. Ángel Rama mira con recelo ciertos expedientes de esta agenda sugiriendo que no pocos indigenismos han sido bandera de herederos de la autoridad colonial:

\section{El indigenismo, sobre todo, en sus sucesivas olas desde el siglo XVIII aludido, ha sido bandera vengadora de muchos nietos de gachupines y europeos, aunque lo que en realidad éstos hicieron desde la \\ Emancipación, llegada la hora del cumplimiento de las promesas, no les acredita blasones nobiliarios (RAMA, 2008, p. 15).}

Efectivamente, algunos indigenismos han servido para consolidar la construcción de las identidades nacionales para las cuales el indígena ha constituido componente, y esto se ha reflejado también en las literaturas nacionales - como observa Ureña - . La constitución heterogénea - étnica, cultural y lingüísticamente hablandode las sociedades latinoamericanas no ha podido ser eludida por estas agendas, pero en ocasiones sus programas han asimilado lo indígena tanto como componente así como materia prima desde una posición - que igualmente puede ser puesta bajo sospecha- que reproduce los paradigmas coloniales de apropiación de las que han sido objeto territorios y comunidades; y aun desde perspectivas progresistas las operaciones en pos de una visibilidad de las realidades y universos indígenas se despliegan, paradójicamente, a instancias de una invisibilidad. (¿No es acaso el caso de la lectura de José Carlos Mariátegui? Mientras afirma que el programa indigenista de la literatura no puede sino ofrecernos una mirada que tienda a "idealizarlo y estilizarlo" sugiere que una literatura indígena "si debe venir, vendrá 
a su tiempo. Cuando los propios indios estén en grado de producirla" (MARIÁTEGUI, 2007, p. 283).

De todos modos tales lecturas no pueden si no ser leídas en un proceso más amplio de reflexión que implique una venia para la tentativa y el error, y para las palabras con las que en sus respectivos tiempos se contaba para nombrar una escena que todavía no contaba con léxico propio en un horizonte incluyente.

Cornejo Polar, asimismo, destaca una "fractura entre el universo indígena y su representación indigenista" (CORNEJO POLAR, 1978, p. 14), aduciendo que tal escisión responde al hecho de que el referente y el destinatario de tales producciones simbólicas no eran el mismo: es decir, la representación indigenista del indígena estaba destinada a un público no-indígena.

El caso de la literatura paraguaya es paradigmático dado el estatuto de insularidad cultural y mediterraneidad geográfica - sin eficientes mecanismos de integración regional- que habría sido observado por aquellos autores que fueron capaces de franquear el cerco local - fundamentalmente por el empuje del exilio-; y, por otro lado, por la constatación - inclusive por alguno de ellos - de que la sociedad paraguaya y sus producciones simbólicas han pasado desapercibidas por las miradas críticas que sobre América Latina se han arrojado como conjunto; salvo excepciones, y la obra de estos autores y sus afirmaciones son algunas de ellas.

Se puede aseverar también que en la construcción y consolidación de la identidad nacional paraguaya en función del Estado paraguayo, tanto a partir de su emancipación de la Corona Española como en los años que le sucedieron, la literatura ha ocupado un papel marginal - acaso no así el discurso histórico y el ensayo político puesto en circulación fundamentalmente a través de la prensa-.

Quizás otra de las razones esté fundada en las condiciones lingüísticas de una sociedad mayoritariamente guaraní hablante: lengua que si bien había producido literatura escrita ya durante las misiones jesuíticas, había visto frenado un proceso de consolidación literaria - entendida aquí como escritura - con la expulsión de los jesuitas; y episodios insólitos como la producción de periódicos de trinchera en guaraní durante la Guerra contra la Triple Alianza a finales del siglo XIX, no vieron continuidad, como era de esperarse tras la hecatombe que tal enfrentamiento bélico supuso. (Y sin embargo la lengua persistió, se transformó y han proliferado poemas populares difundidos oralmente y a través de la música). La lengua guaraní, asimismo, había sido impugnada como signo de atraso y eventualmente celebrada como marca identitaria en diversos momentos.

Los gobiernos autoritarios, los más de los ellos[5], prestaron poca atención a la producción simbólica en Paraguay; e inclusive se podría afirmar que la dictadura stronista, que funcionó más por negatividad que por promoción de valores culturales, vio a pesar de sus esfuerzos la sobrevivencia insular de prácticas rituales y estéticas que, lejos de la eficacia de sus vigilancias han alcanzado algún grado de 
persistencia. Ticio Escobar reflexiona en torno a la posibilidad de pensar en una cultura stronista - fundada apenas en un militarismo auto-reflexivo, una precaria folklorización de ciertos valores "criollos" o mestizos y la negación de la diferencia como falla o marca de influencia exterior - :

Es que para la dictadura militar stronista, oscurantista y retrógrada, los haceres simbólicos no constituían una dimensión fundamental de la sociedad sino un conjunto de prácticas extravagantes, apenas tolerables en el mejor de los casos (...). Así, en el Paraguay, ni el nacionalismo estatal se preocupó en desarrollar proyectos de conservación del patrimonio (museos folklóricos o histórico épicos, adecuada documentación del "acervo tradicional patrio", etc.) ni el populismo impulsó los característicos programas divulgacionistas, ni el desarrollismo generó un mecenazgo empresarial sistemático más allá de apoyos dispersos y poco generosos (ESCOBAR, 1992, p. 27).

Los procedimientos que buscaron la incorporación de lo indígena a la cultura nacional paraguaya - reducido estrictamente a la cultura Guaraní, a pesar de casi una veintena de grupos étnicos distribuidos por el territorio paraguayo[6]fraguaron igualmente la invisibilización del indígena que, a pesar de sobreviviente y real, es visto casi estrictamente en clave ancestral. Así, el nacionalismo paraguayo ha celebrado - hasta hoy - supuestos valores Guaraníes que estarían presentes en la sociedad paraguaya, fundada, según el mito, en el mestizaje hispano-guaraní.

En El mito del arte y el mito del pueblo, Ticio Escobar observa que este indigenismo es el responsable de "encubrir los aspectos contradictorios y escamotear diferencias y tensiones internas" (ESCOBAR, 2010, p. 93), a la par que "anima un Pueblo heroico que avanza en épica gesta desde su directo antepasado guaraní hacia algún futuro glorioso y triunfal” (Ídem); y, sin embargo, mientras a través de las formulaciones del discurso nacionalista los indígenas - en particular los Guaraníes, se reitera, para el caso paraguayo - " "son convertidos en savia de la nacionalidad y colocados en los altares de la tradición, los sectores populares y las etnias actuales son expulsados de la escena" (Ibídem, p. 94).

El propio Rubén Bareiro Saguier había sido crítico de este indigenismo. Su posición es revisada por Bartomeu Melià a partir de una presentación del escritor en el Congreso de Americanistas de París (1976) donde presentaba un estudio sobre La generación nacionalista-indigenista del Paraguay y la cultura guaraní. Bareiro Saguier analiza la obra de poetas y ensayistas y, según Melià, descubre en todos ellos "contradicciones derivadas esencialmente del positivismo evolucionista de la época, que en fin de cuentas sólo aprecia a los Guaraníes en cuanto habrían tenido una "civilización" comparable con otras grandes civilizaciones" (MELIA, 2011, p. 94), o estilizando y vaciando así de lo Guaraní a los Guaraníes[7].

En una compilación de artículos publicada en 1990, Bareiro Saguier admite haberse encantado con este indigenismo en sus años de juventud, para constatar sólo posteriormente "la alienación que implicaba esa clase de construcciones de la 
representación mental al servicio de una cierta ideología" (BAREIRO SAGUIER, 1990, p. 33), sin dejar de señalar que, como él, aun autores con posiciones progresistas - como Manuel Ortiz Guerrero - son víctimas de esta ideología nacionalista que instrumentalizó el indigenismo[8].

Si bien este indigenismo nacionalista ha sobrevivido en Paraguay, no se ha reflejado en la obra de Augusto Roa Bastos ni Rubén Bareiro Saguier quienes, a sus maneras, fueron indigenistas. Bajo el título de Las Culturas Condenadas (1978), Augusto Roa Bastos publica una serie de artículos y ensayos de autores diversos que buscan llamar la atención hacia la realidad indígena del Paraguay, y particularmente hacia la situación de genocidio que algunas de estas culturas estaban atravesando, como el título bien anticipa. Por su parte, Rubén Bareiro Saguier, especialista en lengua guaraní, realizó una gran tarea de compilación de literatura oral y escrita guaraní en Literatura Guaraní del Paraguay (1980) que tuvo cierta circulación nacional[9].

Conociendo la literatura Guaraní, deslumbrados por sus espesores líricos, no es extraño que la obra de estos autores no haya tenido pretensiones miméticas; no hay, dicho sea de paso, ni en la música popular del Paraguay, ni en sus artes visuales una intención de imitación de las formas indígenas, cuestión que aunque pueda ser leída como negación del componente indígena en la cultura nacional paraguaya, es explicada por Roa como rasgo insalvable de superioridad estética de la primera frente a la segunda que se da en llamar criolla o mestiza. Refiriéndose a la poesía Guaraní, Roa Bastos afirma que:

estos cantos no tienen parangón en toda la literatura paraguaya escrita en castellano hasta el presente. Orgullosa de una tradición cultural en la que continúan actuando o predominando los vestigios de la dominación y la dependencia o, en todo caso, los signos de una hibridación que no ha alcanzado todavía a plasmar su propio sistema y pertinencia, los textos de esta literatura mestiza escrita en castellano, segregada de sus fuentes originarias, se apagan, carecen de consistencia y de verdad poética ante los destellos sombríos de los cantos indígenas tocados por el sentimiento cosmogónico de su fin último en el corazón de sus culturas heridas de muerte (ROA BASTOS, 2011, p. 23).

Así, se podría sugerir que el indigenismo de Roa Bastos y Bareiro Saguier se concentró más bien en la articulación de energías intelectuales para la exposición tanto de una denuncia como de la riqueza cultural de estas sociedades subalternas tan tenidas a menos por el coloniaje de procedencias y fechas diversas. ¿Es acaso el canon de la literatura moderna canonizando la literatura indígena?[10].

Pero luego está la cuestión de la lengua. El guaraní paraguayo que, como hemos dicho, no es guaraní Guaraní - o que no se corresponde con las diversas lenguas Guaraníes que a duras penas sobreviven aún hoy en el Paraguay[11]—, aunque haya sido una preocupación de estos autores, apenas ha sido empleada para su producción literaria. Mientras se puede afirmar que las condiciones de exilio supusieron la ampliación de un horizonte de interlocutores posibles para cuyos 
efectos el empleo del castellano resulta, por razones obvias, más eficiente, lecturas críticas han sugerido que, especialmente en la obra de Roa Bastos, se ha querido fraguar alguna suerte de rescate de la lengua guaraní, en su escritura en castellano.

\section{LA CUESTIÓN DE LA LENGUA}

Revisada por la crítica y la teoría literaria que desde América Latina se ha producido, la preocupación en busca de una expresión propia no estuvo ajena de las reflexiones en torno a la lengua; y así, también, ha habido literatura que a través de procedimientos diversos han tratado de dar cuenta de las especificidades lingüísticas y de las tradiciones heterogéneas que atraviesan el territorio latinoamericano - ya sea a través de acopios y traducciones en tensión entre lo indígena, lo mestizo y lo europeo; ya sea en la asunción de hibridaciones y transculturaciones-.

Ya en sus Seis ensayos en busca de nuestra expresión Pedro Henríquez Ureña habla acerca de una complejidad vinculada a la lengua en la literatura en tanto los escritores escriben en castellano a pesar de la existencia de lenguas indígenas vivas: "El hombre de letras, generalmente, las ignora", sugiere, "y la dura tarea de estudiarlas y escribir en ellas lo llevaría a la consecuencia final de ser entendido entre muy pocos" (UREÑA, 1960, p. 245).

Mientras sostiene que "la única manera que el nombre de América Latina no sea invocado en vano, es cuando acumulación cultural interna es capaz de proveer no sólo de "materia prima", sino de una cosmovisión, una lengua, una técnica para producir las obras literarias" (RAMA, 2008, p. 25), Ángel Rama comenta la obra de José María Arguedas y Roa Bastos desentrañando algunas de las maniobras que en el interior de la lengua castellana son llevadas a cabo para dar cuenta de las especificidades lingüísticas en un marco literario unitario:

En el caso de los personajes que utilizan algunas de las lenguas autóctonas americanas, se procura encontrar una equivalencia dentro del español, forjando una lengua artificial y literaria (Arguedas, Roa Bastos, Manuel Scorza) que sin quebrar la tonalidad unitaria de la obra permite registrar una diferencia en el idioma (Ibídem, p. 49).

Así sería introducida la variante idiomática en el interior de la lengua del propio narrador, en este caso el castellano.

Un poco más arriesgada, la lectura de Saúl Sosnowski también pondera y equipara la obra de Roa Bastos con la de Arguedas sugiriendo que:

En sus respectivas obras, el quechua y el guaraní no están relegados a letras cursivas o a notas explicativas que denotan simbólicamente la 
sumisión de los vencidos sino que, al contrario, rigen desde la centralidad del texto con la fuerza vital de los sobrevivientes (SOSNOWSKI, 2015, p. 71).

Quizás valga la pena reiterar, en este punto, que el guaraní paraguayo, aunque subalterna, no es estrictamente la lengua "de los vencidos" y que es, de muchas maneras, una lengua colonial[12]. Quizás la trampa del nombre, de la ambigüedad patente en el nombre guaraní, dificulte transparencias aún para quienes, conocedores de la lengua y de la diferencia entre la cultura mestiza paraguaya, eminentemente colonial, y la cultura Guaraní, como Rubén Bareiro Saguier, reproducen en su discurso nociones que hoy, a la luz de numerosas investigaciones, vemos con mayor claridad.

Sosnowski afirma, por ejemplo, que en Yo el Supremo Roa Bastos reproduce "la estructura del relato indígena como la tonalidad de su lengua en un marco formal innovador" (Ibídem, p. 72). ¿A qué relato se refiere si los cantos compilados por León Cadogan, a los que Roa Bastos había tenido acceso, no comparten estructura ni ritmo con su novela cumbre, y si en 1978, después de la publicación de la misma, afirmaba que tales cantos no tienen parangón con la literatura escrita en castellano hasta entonces?

El propio Bareiro Saguier comparte las tesis de Sosnowski y Rama al describir los procesos por los cuales pasó la escritura roabastiana hasta alcanzar la voz excepcional de Yo el Supremo:

En la escritura de Augusto Roa Bastos, la presencia de los valores guaraníes es menos aparente, en acuerdo con la realidad cultural del pueblo paraguayo, mestizo, y se opera especialmente a nivel de la lengua. Tres etapas marcan la evolución literaria de Roa Bastos, en lo que concierne a esa presencia. El autor comenzó intercalando palabras o frases en guaraní dentro del discurso narrativo, con la consiguiente traducción al pie de página. Poco satisfecho, pronto abandonó este procedimiento y, a partir de su novela Hijo de hombre (1960), las expresiones en la lengua aborigen, en lugar de ser traducidas, son explicadas en el contexto de la narración, mediante un desarrollo metafórico del significado. La elaboración lingüística de Roa Bastos está próxima de la realizada por José María Arguedas. El español es modificado desde el interior de la lengua empleada, mediante la presencia subrepticia de la estructura del guaraní, de sus ritmos y modulaciones, sus quiebras y giros, de la textura metafórica del idioma indígena. En su última novela Yo el Supremo (1974), esta tarea se intensifica, pues existe una elaboración realizada no sólo a partir de la sintaxis, sino del proceso genético de las palabras en la lengua aborigen (BAREIRO SAGUIER, 1990, p. 46).

"Lengua aborigen", dice Bareiro Saguier, "idioma indígena", contradiciendo la primera aseveración de que, correspondiente con la realidad mestiza de la sociedad 
paraguaya, la presencia de los “valores guaraníes" sería menos obvia en la obra de Roa Bastos que en otras producciones indigenistas latinoamericanas; sin mencionar el hecho de que la lengua guaraní conocida por Roa Bastos es el guaraní paraguayo. "Nuestra inquietud se explica", dice Pedro Henríquez Ureña: "Contagiados, espoleados, padecemos aquí en América urgencia romántica de expresión. Nos sobrecogen temores súbitos: queremos decir nuestra palabra antes de que nos sepulte no sabemos qué inminente diluvio" (UREÑA, 1960, p. 244). Quizás este apuro por decir aquello con lo cual aún no se cuenta con palabras para nombrar obliga a construir un discurso a empellones, y debe ser leído con cierta condescendencia - las aportaciones de Rubén Bareiro Saguier son igualmente significativas para el conocimiento de la cultura Guaraní y de la lengua guaraní de los paraguayos, a pesar de esta pequeña contradicción fundada en la ambigüedad del nombre guaraní-. Bareiro Saguier explica de qué manera el guaraní interfiere en el castellano de la prosa roabastiana en Yo el Supremo:
La unidad significativa se genera en guaraní por aglutinación o polisíntesis, contrariamente al procedimiento de la flexión, propio a las lenguas neo-latinas. La adición de prefijos y sufijos va modificando la idea central, o radical. La aplicación de semejante sistema a una prosa escrita en castellano da como resultado una lengua que pierde la precisión racional del significado, y se enriquece por la ambigüedad poética que impregna el significante. En consecuencia, cada elemento expresivo y el conjunto de la escritura adquieren una multiplicidad deslumbrante de sentidos. A este aspecto lingüístico hay que agregar la incorporación espontánea de una serie de valores culturales guaraníes que, como la lengua, han sobrevivido al condicionamiento de la dominación y al proceso del mestizaje (BAREIRO SAGUIER, 1990, p. 46).

Bareiro Saguier que en líneas previas sugería que la presencia de valores culturales guaraníes en la obra de Roa Bastos era escasa, afirma que en su obra Roa Bastos los incorpora espontáneamente - sin especificar qué valores - , asegurando que en los sujetos mestizos éstos habrían sobrevivido.

Interrogando la invisibilidad del guaraní en sí en los relatos de la sociedad paraguaya, el antropólogo Bartomeu Melià se pregunta si “ ¿somos guaraníes los paraguayos?" (MELIA, 2011, p. 93); termina aseverando que acaso "la presencia guaraní en la sociedad paraguaya se manifiesta, sobre todo a través de dos vías: la lingüística y la económica" (Ibídem, p. 101), con la salvedad de que su lengua es, hoy, fundamentalmente otra.

¿Cómo leer, sin embargo, esta transfiguración de la lengua, esta pretendida pervivencia de la lengua otra en el interior de otra lengua? Quizás esta sea una marca de modernidad. Refiriéndose a las crónicas como modelo de escritura fundante en América Latina, Cornejo Polar observa que "el hecho de que casi unánimemente invoquen al rey (...) es un gesto cortesano, pero también, más profundamente, un signo del sistema de comunicación que preside el enunciado cronístico: el rey, la metrópoli, es su lector" (CORNEJO POLAR, 1978, p. 13). 
Ampliado el horizonte de interlocutores, la constatación de la insularidad cultural del Paraguay bajo regímenes autoritarios que la obra roabastiana describe puede ser leída, acaso, como un llamado de auxilio y como un deseo de que una modernidad, entendida como una escena posible con formas democráticas, pase por donde no ha pasado.

Domingo Miliani sugiere que a partir de los avances de la lingüística ya es posible construir una historia de la literatura latinoamericana que rebase las fronteras de la lengua y que contemple las escenas heterogéneas que ésta describe, ya sea en las múltiples lenguas indígenas vivas, las lenguas coloniales o mestizas:

La analogía cultural de América Latina es historiable, así, en los signos que rebasan el nivel de lengua, no importa que la literatura sea escrita en español, portugués, créole haitiano, inglés jamaiquino, slang trinitario; o hablada y transmitida en quechua, náhuatl, maya, guaraní, etc. Las recurrencias de un pasado colonial común y una voluntad de liberación unen destinos sociales, nutren la textualidad transverbal, están presentes y son recuperables en el plano semántico de la literatura (MILIANI, 1987, p. 110-111).

Quizás a la luz del concepto de transverbalidad[13] pueda ser leída una producción que ha venido consolidándose en Paraguay. A partir de la última década del siglo $\mathrm{XX}$, autores paraguayos, brasileños y argentinos han osado hacer del guaraní lengua literaria, aun cuando ésta se dijera en la encrucijada fronteriza, amenazada por las lenguas coloniales que la acorralan. A este periodo corresponde la obra del escritor brasileño Wilson Bueno, cuya novela Mar paraguayo (1992) está escrita en una mezcla artificial de guaraní, castellano y portugués - que no se corresponde necesariamente con el habla coloquial en la que tales interferencias se producen en escenas fronterizas - ; su obra dialoga con la del escritor paraguayo Jorge Canese quien, a partir del contacto con Bueno a finales de los años 80 , ve su obra potenciada y constituye uno de los primeros casos de literatura urbana en la que la interferencia, primero entre castellano y guaraní, luego con el portugués es trabajada como materia: escritores contemporáneos, entre los que cabe destacar a Douglas Diegues y Cristino Bogado, reconocen en ambos piezas fundantes para articular una lengua literaria artificial, el portunhol selvagem, que a la manera de Bueno en Mar paraguayo opera en la encrucijada de las lenguas, en escenas transterritoriales signadas por un lado por una reciente apertura democrática y cultural en Paraguay y asimismo por una escena colonial que ha venido transformando drásticamente su territorio y las economías de comunidades campesinas e indígenas a la luz de una modernidad atropellada, heredera de la dictadura stronista.

\section{notas de rodapé}


[2] Augusto Roa Bastos nació en Asunción, en 1917. Fue novelista, cuentista, poeta y guionista. Gran parte de su obra fue producida en el exilio; primero, en la Argentina, luego, en Francia. La cuestión del poder es el tema central de gran parte de su obra, entre las cuales son piezas destacadas las novelas Hijo de Hombre (1960), Yo el Supremo (1974) y El Fiscal (1993), que constituyen su denominada Trilogía del Poder. Como guionista colaboró con diversas producciones cinematográficas argentinas. Falleció en Asunción en 2005.

[3] Rubén Bareiro Saguier nació en Villeta, en 1930. Fue un escritor y poeta paraguayo, uno de los primeros en tener una importante formación académica en el área de Letras: realizó estudios de literatura en la Universidad Nacional de Asunción y se doctoró en Letras y Ciencias Humanas por la Université Paúl Valéry-Montpellier III, en Francia. Pasó su infancia en el interior, no muy lejos de la capital paraguaya, a orillas del río Paraguay. Estuvo preso varias veces durante diversos regímenes autoritarios. Vivió en Francia a partir de 1962, donde publicó sus primeros libros de poemas. Recibió el Premio Casa de las Américas en 1971, y, en una visita al Paraguay, fue preso por la policía de Alfredo Stroessner. Diversos autores se movilizaron exigiendo su liberación (entre ellos Jean-Paul Sartre, Roland Barthes, Fernando Savater, y otros), y fue finalmente liberado y expulsado del país hasta 1989.

[4] Refiriéndose a esta adscripción de Arguedas y Roa Bastos, Saúl Sosnowski afirma: "Cabe notar que en ambos casos su reconocimiento internacional ha sido posterior a las figuras centrales del boom y que ambos fueron fuertemente cuestionados por algunos de los arquitectos ideológicos que contribuyeron a ese fenómeno editorial" (SOSNOWSKI, 2015, p. 73).

[5] No corresponde hablar en el caso de Paraguay de "retorno a la democracia" después de la caída stronista, dado que nunca había tenido experiencias democráticas.

[6] Y acaso se deba al hecho de que la lengua guaraní sea la única lengua indígena que ha permeado la frontera de las comunidades indígenas, diseminándose en la sociedad paraguaya. [7] Nótese, por ejemplo, una de las figuraciones que ha alcanzado más difusión de lo indígena Guaraní en la canción India (de 1928), de José Asunción Flores, con letra del poeta modernista residual Manuel Ortiz Guerrero: "India, bella mezcla de diosa y pantera/doncella desnuda que habita el Guairá", o en La canción del Mimby (Juan Cristóbal Balbi; se estima que de los años 40) "Ceñida a la frente radiante corona, la reina morena/viene de la selva con regio atavío jepe ipynandi (aunque está descalza)(...)/la lira exquisita dormida en su alma despierta y se agita".

[8] En su Mundo Guaraní, Bartomeu Melià revisa las representaciones de los Guaraníes a lo largo de la historia, destacando los usos del nacionalismo indigenista del siglo XX en la producción ensayística de escritores paraguayos.

[9] La obra compilatoria de Curt Nimuendaju, en la década del 10, y la de León Cadogan en los años 40 constituyen algunas de las primeras en circular internacionalmente, especialmente en el ámbito académico.

[10] Walter Mignolo afirma que si bien la literatura canónica latinoamericana se dice en las lenguas coloniales no ha suprimido las culturas amerindias y las ha incorporado de alguna manera: "En Latinoamérica, por ejemplo, la formación oficial del canon se basó en la lengua y en los valores de las culturas colonizadoras más importantes (española y portuguesa) y ocupó el lugar del canon silenciado (pero no suprimido) de las culturas amerindias" (MIGNOLO, 1998, p. 241). [11] "lenguas guaraníes, tan amenazadas precisamente por el guaraní paraguayo" (MELIA, 2011, p. 108).

[12] Una lengua española más, dirá Bartomeu Melià.

[13] Domingo Miliani acota el horizonte ambiguo del concepto transverbal, sugiriendo que la interferencia lingüística se daría no sólo en un plano léxico o sintáctico sino que estaría presente también en un nivel semántico del discurso, y, en particular, del discurso literario.

\section{bibliografia}

BAREIRO SAGUIER, Rubén. De nuestras lenguas y otros discursos. Asunción: Universidad Católica Nuestra Señora de la Asunción. Biblioteca de Estudios Paraguayos, V. 34, 1990.

BAREIRO SAGUIER, Rubén (comp.). Literatura Guaraní del Paraguay. Caracas: Ayacucho, 1980. 
CORNEJO POLAR, Antonio. "El indigenismo y las literaturas heterogéneas: su doble estatuto socio-cultural” In: Revista de Crítica Latinoamericana. Lima: Latinoamericana Editores. Año IV, Nº 7-8, 1978.

ESCOBAR, Ticio. El mito del arte y el mito del pueblo. $2^{\text {a }}$ edición. Asunción: Centro de Artes Visuales/Museo del Barro, 2010.

ESCOBAR, Ticio. Textos varios sobre cultura, transición y modernidad. Asunción: Agencia Española de Cooperación Internacional/Centro Cultural de España Juan de Salazar, 1992.

MARIÁTEGUI, José Carlos. "El proceso de la literatura" In: 7 ensayos de interpretación de la realidad peruana. Caracas: Fundación Biblioteca Ayacucho, 2007.

MELIA, Bartomeu. Mundo Guaraní. 2a edición. Adriana Almada (ed.). Asunción: Banco Interamericano de Desarrollo, 2011.

MIGNOLO, Walter. "Los cánones y (más allá de) las fronteras culturales (o ¿de quién es el canon del que hablamos?) In: SULLA, Enric (comp.). El canon literario. Madrid: Arco/Libros, 1998.

MILIANI, Domingo. "Historiografía literaria latinoamericana. Más alá del inventario y de la anécdota. La historia posible” In: PIZARRO, Ana (coord.). Hacia una historia de la literatura latinoamericana. México: El Colegio de México/Universidad Simón Bolívar, 1987.

RAMA, Ángel. Transculturación narrativa en América Latina. 2da. Ed. Buenos Aires: Ediciones El Andariego, 2008.

ROA BASTOS, Augusto. Culturas Condenadas. $2^{\text {a }}$ edición. Asunción: Servilibro, 2011.

SOSNOWSKI, Saúl. Cartografía de las letras hispanoamericanas: tejidos de la memoria. Villa María: Eduvim, 2015.

UREÑA, Pedro Henríquez. Seis ensayos en busca de nuestra expresión. México: Fondo de Cultura Económica, 1960. 